\title{
The Role of Altered Bile Acid Metabolism in the Steatorrhea of Experimental Blind Loop*
}

\author{
Young S. Kim,† Norton Spritz, $\ddagger$ Morton Blum,§ Jose Terz,† and \\ Paul Sherlock \\ (From the Lipid Metabolism Laboratory of the Second [Cornell] Medical Division, Bellevue \\ Hospital; the Division of Experimental Surgery and Physiology of the Sloan-Kettering \\ Institute for Cancer Research; the Departments of Medicine and Surgery, Me- \\ morial Hospital for Cancer and Allied Diseases; and the Department of \\ Medicine, Cornell University Medical College, New York, N.Y.)
}

Although it is well documented that blind loop of the small intestine, either spontaneously occurring (2) or experimentally produced (3-5), is associated with steatorrhea, the mechanism for this abnormality has not been demonstrated. A pathogenic role of bacteria is strongly suggested in this and closely associated conditions by the observations that bacterial overgrowth of the small bowel occurs $(6,7)$ and that the steatorrhea usually responds to antibacterial therapy $(2,4,5)$.

In the present study in vivo alteration of bile acid metabolism in dogs with experimental blind loop steatorrhea was investigated. Marked differences from normal were observed, the most notable abnormality being considerable conversion of conjugated to unconjugated acids within the small bowel of the experimental animals.

Two experimental findings suggest that this alteration of bile acid metabolism plays a role in blind loop steatorrhea. First, intraluminal micelle formation, a probable step in fat absorption that occurs optimally in the presence of conjugated bile

* Submitted for publication October 11, 1965 ; accepted March 7, 1966.

This study was supported by U. S. Public Health Service grants NB 03346-04, ZA 5091, and Clinical Research Training grant CA 5110-04 from the National Cancer Institute. It was presented at the general session of the American Federation for Clinical Research on May 2, 1965, Atlantic City, N. J., and has appeared in part in abstract form (1).

$\dagger$ Clinical research trainee, National Cancer Institute.

$\ddagger$ Career Investigator (I-128), Health Research Council, New York, N. Y. Address requests for reprints to Dr. Norton Spritz, Lipid Metabolism Laboratory, Second (Cornell) Medical Division, Bellevue Hospital, First Ave. and 26th St., New York, N. Y. 10016.

§ Postdoctoral fellow (1F2AM-23, 35501), U. S. Public Health Service. acids, was shown to be impaired. Second, feeding of conjugated acids to animals with steatorrhea resulted in amelioration of the fecal fat loss.

\section{Methods}

Mongrel dogs weighing 32 to 38 pounds were used in all studies. Both control and experimental animals were individually caged, and food intake consisting in all animals of Purina dog chow and meat dog chow ${ }^{1}$ was measured for each daily feeding. This feeding provided an average of $55 \mathrm{~g}$ of fat as determined by fat analysis and a total of 954 calories. This was offered as a single feeding and most was consumed within 1 hour. There was no significant difference in intake between operated and control dogs. When sodium taurocholate ${ }^{2}$ was administered, 5 or $10 \mathrm{~g}$ was thoroughly mixed with the feeding, and this mixture was rapidly and completely consumed by both control and operated animals.

In experiments requiring a single liquid fat-containing feeding, $320 \mathrm{ml}$ of formula was used. This contained $14 \mathrm{~g}$ of safflower oil, which constituted $40 \%$ of its caloric content.

Cholesterol-4- ${ }^{14} \mathrm{C}^{3}$ was administered intravenously in 0.5 to $1.0 \mathrm{ml}$ of ethyl alcohol.

Operative procedures. Figure 1 is a schematic representation of the results of the surgical procedure for the construction of the blind loop as slightly modified from that described by Tönnis and Brusis (8). The stoma of the loop was $5 \mathrm{~cm}$ below the ligament of Treitz, and the loop was approximately $48 \mathrm{~cm}$ in length and was "self-filling," in that the direction of peristaltic flow was from the stoma toward the blind end. In experiments in which gastric instillation and sampling of jejunal content were carried out, the dogs were maintained under light sodium pentobarbital anesthesia. The gastric tube (no. 22F) and intrajejunal tube (no. 16F) were placed through a small gastrotomy incision, and under direct vision, the latter was fixed $20 \mathrm{~cm}$ below the blind loop

\footnotetext{
${ }^{1}$ Kennel Food Supply Division, Hygrade Food Products Corp., Detroit, Mich.

2 Nutritional Biochemicals, Cleveland, Ohio.

${ }^{3}$ SA $50 \mu \mathrm{c}$ per mg, New England Nuclear Corp., Boston, Mass.
} 


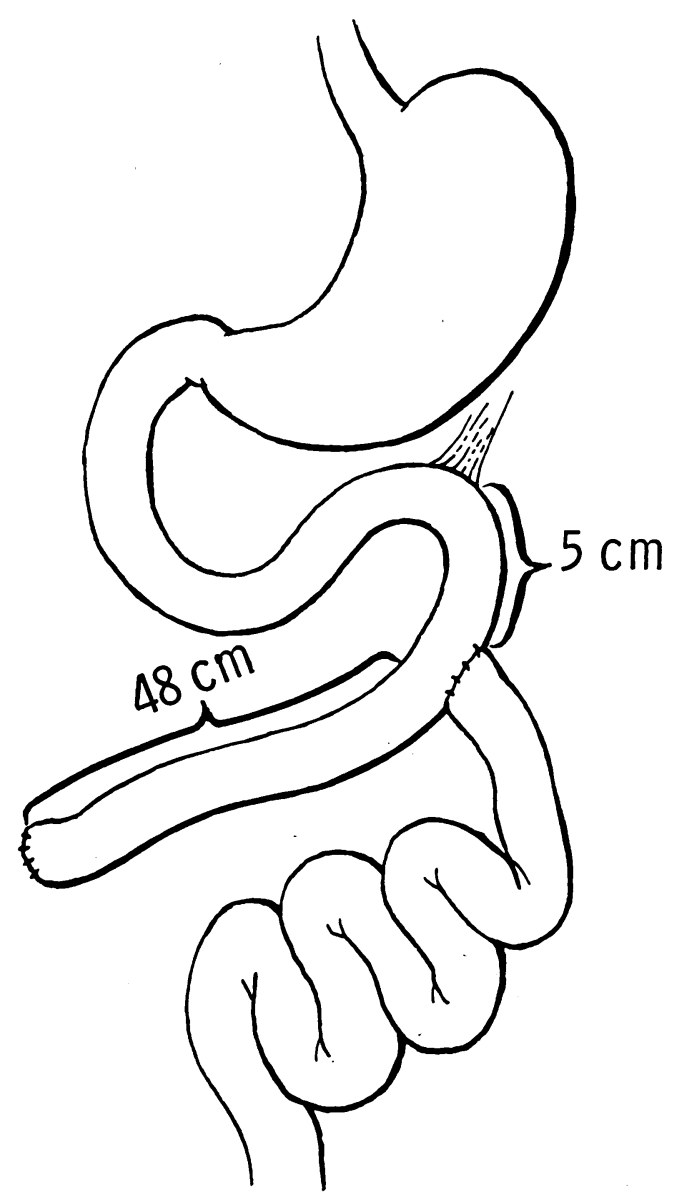

Fig. 1. Schematic Representation of Surgically ProDUCED BLIND LOOP.

stoma and was shown to remain in this position when re-examined at the end of the experiment. In the animal in which the contents of the blind loop were repeatedly sampled, the loop was detached from the jejunum at the beginning of the study. The contents of the loop were made available through a metallic button placed in the blind end.

Chemical procedures. Fecal fat was determined on 4-day pools of homogenized feces by the method of Saxon (9). Micellar phase lipid in jejunal content was separated as described by Hofmann and Borgström (10), and the lipid in that phase as well as the total lipid of the unspun specimen was determined by the method of Amenta (11). Extraction of bile and jejunal content for bile acids was carried out with 5 vol of isopropanol at $65^{\circ} \mathrm{C}$ for 30 minutes, and bile acid fractionation was carried out by Florisil column chromatography. The details of these methods and their verification are described in a previous publication (12). Radioactivity was detected by a Tri-Carb liquid scintillation counter using benzoic acid- ${ }^{14} \mathrm{C}$ as an internal standard for quench correction. Thin layer chromatography of intestinal content lipid was carried out on $0.5-\mathrm{mm}$ silicic acid chromatoplates (13) developed in acetic acid: ethyl ether: heptane $(1: 49: 50)$.

\section{Results}

Fecal fat excretion. Steatorrhea of up to $56 \%$ of dietary fat was noted 2 to 7 months after the construction of the blind loop in all 12 operated dogs. Fat excretion exceeded the normal by more than $2 \mathrm{SE}$ from the mean in each instance, and mean excretion rate and standard error were $21.2 \pm 3.7 \%$ of dietary fat for the operated group compared to $6.6 \pm 0.3$ for 11 controls $(p<0.001)$. Weight loss occurred in all operated animals, reaching a maximum of $37 \%$ of body weight in one animal.

In two dogs, one with $19 \%$ and the other with $22 \%$ fecal fat loss, $0.5 \mathrm{~g}$ per day of tetracycline was administered orally for 20 days, and steatorrhea fell to $7 \%$ in both instances with cessation of weight loss. In one dog in which continuity between the blind loop and the jejunal lumen was interrupted, fecal fat loss fell from 17.6 to $6.2 \%$ after 18 days.

Bile acid conjugation in intestinal content and bile. Four normal and four blind loop dogs received $20 \mu \mathrm{c}$ of cholesterol-4- ${ }^{14} \mathrm{C}$ intravenously. Twenty hours later, the per cent of bile acid radioactivity in conjugated and nonconjugated forms was determined in jejunal content obtained in the fasting state in each instance and in one control and blind loop dog 30,60, and 90 minutes after instillation of a fat-containing formula (Table I, blind loop and normal dogs no. 1).

In control dogs, bile acid conjugation in the fasting jejunal content ranged from 74.7 to $96.5 \%$, compared to 2.5 to 37.3 in the three operated dogs with significant steatorrhea. In the single operated dog (blind loop dog 4) with minimal steatorrhea (11\%), bile acid conjugation was $94.4 \%$. In specimens of jejunal content obtained for up to 90 minutes after a fat-containing feeding, conjugation remained below $57 \%$ in the blind loop dog with steatorrhea (blind loop dog 1) compared to 97.5 to $98.9 \%$ in a similarly treated control (normal $\operatorname{dog} 1)$. These studies were carried out in unanesthetized animals in which the jejunal collection tubes had been placed 1 day before the experiment. With the exception of blind loop dog 2 , in which biliary bile acids were only $45.5 \%$ conju- 
TABLE I

Per cent conjugated bile acid radioactivity in jejunal content and bile in normal and blind loop dogs*

\begin{tabular}{|c|c|c|c|c|c|c|}
\hline & \multirow{3}{*}{$\begin{array}{c}\text { Fecal fat } \\
\text { losst }\end{array}$} & \multicolumn{5}{|c|}{ Per cent bile acids conjugated } \\
\hline & & \multirow[b]{2}{*}{ Bile } & \multicolumn{4}{|c|}{ Jejunal content } \\
\hline & & & Fasting & 30 minutes $\ddagger$ & 60 minutes $\ddagger$ & 90 minutes \\
\hline $\begin{array}{r}\text { Blind loop dogs } \\
1 \\
2 \\
3 \\
4\end{array}$ & $\begin{array}{l}29.0 \\
22.0 \\
19.0 \\
11.0\end{array}$ & $\begin{array}{l}87.8 \\
45.5 \\
94.6 \\
95.2\end{array}$ & $\begin{array}{r}37.3 \\
7.9 \\
2.5 \\
94.4\end{array}$ & 41.0 & 41.6 & 57.0 \\
\hline Normal dogs & $\begin{array}{l}5.4 \\
5.6 \\
6.0\end{array}$ & $\begin{array}{l}99.0 \\
89.6 \\
96.6 \\
98.6\end{array}$ & $\begin{array}{l}96.5 \\
77.3 \\
74.7 \\
76.8\end{array}$ & 97.5 & 98.9 & 98.6 \\
\hline
\end{tabular}

* 20 hours after intravenous cholesterol-4-14 $\mathrm{C}$.

† Per cent of dietary fat.

$\ddagger$ After instillation of fat-containing feeding.

gated, conjugation of gall bladder bile acids ranged from 87.8 to $99.0 \%$ in both groups of animals. Gall bladder content was obtained by direct puncture at laparotomy carried out at the end of each study.

In order to assess further the role of the blind loop itself in the observed alteration of bile acids, bile was obtained 24 hours after the injection of cholesterol-4- ${ }^{14} \mathrm{C}$ from a normal dog in which an exterior bile fistula had been produced. Eighty $\mathrm{ml}$ of this bile was placed into the blind loop segment that had been detached from its intestinal continuity in an operated dog with steatorrhea. Contents of the isolated loop were sampled for 24 hours after instillation of the radioactive bile, and bile acid isotope was fractionated into conjugated and nonconjugated fractions. Before injection, the biliary bile acids were essentially all in the conjugated form. As illustrated in Figure 2, within 6 hours the unconjugated material had risen to $70 \%$ of the total isotopic bile acid.

Fractionation of the nonconjugated acids that appeared in the loop provided further evidence of changes produced during this in vivo incubation. The dihydroxy acids rose to $40 \%$ of the total acids at 6 hours. These, however, could have risen either from deconjugation of the conjugates of the dihydroxy acids in the injected bile or from dehydroxylation of the biliary trihydroxy acids. Monohydroxy acids, on the other hand, are not constituents of bile (14), and their appearance in the intestinal loop at 8 and 24 hours indicates that, in addition to deconjugation, alteration of ring structure also had occurred.

Micelle formation in blind loop jejunal content. Six specimens of jejunal content below the blind loop stoma were obtained from two dogs with steatorrhea 30 to 120 minutes after the intragastric

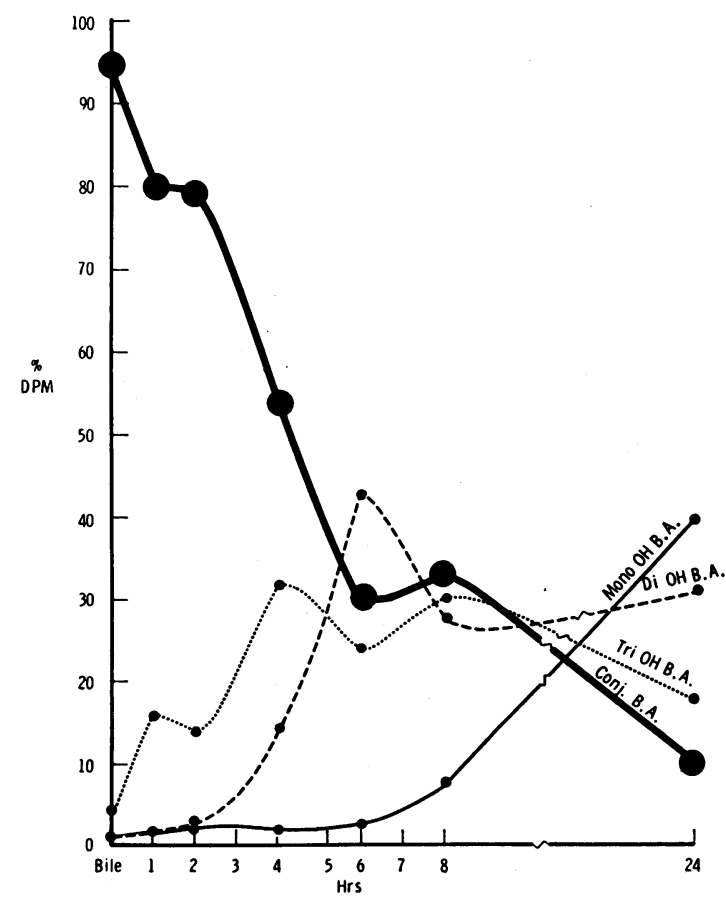

Fig. 2. Changes in isotopic biliary bile acids (BA) AFTER INSTILLATION OF BILE INTO AN ISOLATED BLIND LOOP. The bile was obtained from a bile fistula dog 24 hours after the injection of cholesterol-4- ${ }^{14} \mathrm{C}$. 
TABLE II

Per cent of intestinal content lipid in micellar phase

\begin{tabular}{|c|c|c|c|c|}
\hline \multirow{2}{*}{$\begin{array}{l}\text { Time after fat- } \\
\text { containing meal }\end{array}$} & \multicolumn{2}{|c|}{ Per cent lipid in micellar phase } & \multicolumn{2}{|c|}{ Total lipid in jejunal content } \\
\hline & Normal & Blind loop & Normal & Blind loop \\
\hline minutes & & & \multicolumn{2}{|c|}{$m g / m l$} \\
\hline 30 & $\begin{array}{l}13.4 \\
49.0 \\
82.2\end{array}$ & $\begin{array}{l}2.2 \\
0.0\end{array}$ & $\begin{array}{r}4.3 \\
16.9 \\
29.3\end{array}$ & $\begin{array}{l}17.9 \\
30.0\end{array}$ \\
\hline 60 & $\begin{array}{r}80.5 \\
0.0 \\
65.6\end{array}$ & 0.0 & $\begin{array}{l}12.1 \\
27.6 \\
20.0\end{array}$ & 32.3 \\
\hline 90 & 100.0 & $\begin{array}{l}9.0 \\
1.6\end{array}$ & 39.5 & $\begin{array}{l}5.6 \\
8.9\end{array}$ \\
\hline Mean $\pm \mathrm{SD}$ & $\begin{array}{c}14.0 \\
70.0 \\
89.5 \\
56.5 \pm 35.6^{*}\end{array}$ & $\begin{array}{c}0.4 \\
2.2 \pm 5.0^{*}\end{array}$ & $\begin{array}{r}23.1 \\
4.6 \\
28.2\end{array}$ & 4.8 \\
\hline
\end{tabular}

${ }^{*} \mathrm{p}<0.001$.

instillation of $320 \mathrm{ml}$ of a safflower oil-containing liquid meal. The per cent of lipid in the micellar phase was compared to material from ten specimens similarly obtained from three normal dogs (Table II). Whereas the per cent of micellar lipid did not exceed $9.0 \%$ and averaged $2.2 \pm 5 \%$ in the jejunal specimens from the blind loop animals, it averaged $56.5 \pm 35.6 \%$ in the normal group $(\mathrm{p}<0.001)$, a figure similar to that reported in normal humans (10). Total lipid concentration, also shown in Table II, was comparable in the two groups of animals.

Effect of feeding sodium taurocholate on blind loop steatorrhea. Two dogs with steatorrhea after blind loop construction were each fed 5 and $10 \mathrm{~g}$ of sodium taurocholate for 6 days, and fecal fat loss

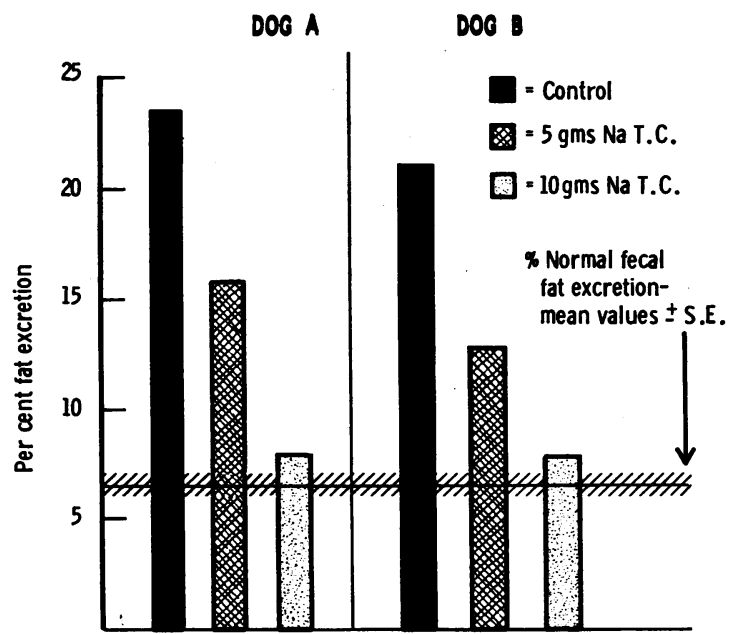

Fig. 3. EFFECT OF SODIUM TAUROCHOLATE FEEDING ON BLIND LOOP STEATORRHEA. for the last 3 days of the feeding was compared to a control period. As illustrated in Figure 3, steatorrhea that was 20.6 and $23.4 \%$ of intake during control collections fell to 12.7 and 15.7 , respectively, on $5 \mathrm{~g}$ of sodium taurocholate and $7.9 \%$ in both animals while they received $10 \mathrm{~g}$ per day. The latter figure was comparable to $7.0 \%$ fat loss observed in the first animal after 20 days of antibiotic therapy and to $6.6 \pm 0.3 \%$ in 11 normal dogs. This decrease in fecal fat loss occurred in spite of diarrhea observed during bile acid feeding in both animals at both dosage levels.

Intraluminal lipolysis. Jejunal content was obtained from two normal dogs and one blind loop $\operatorname{dog} 60$ to 120 minutes after instillation of the safflower oil-containing formula into the stomach. The composition of fatty acid and triglyceride after extraction with ethanol: ethyl ether $(3: 1)$ is depicted in a thin layer chromatoplate (Figure 4). Triglyceride, the major constituent of safflower oil is essentially absent from the intestinal content of both blind loop and control animals. In both instances fatty acid, the major product of triglyceride lipolysis, is present as the main component. Although this nonquantitative demonstration does not establish that lipolysis has proceeded normally in the blind loop animals, it indicates, as shown by others (5), that extensive lipolysis does take place in this situation.

$p H$ of intestinal content. The $\mathrm{pH}$ of intestinal content of three blind loop dogs with steatorrhea and four controls ranged from 6.4 to 6.8 .

Histology of jejunal mucosa. Whole thickness jejunal biopsies were obtained from an area $5 \mathrm{~cm}$ 


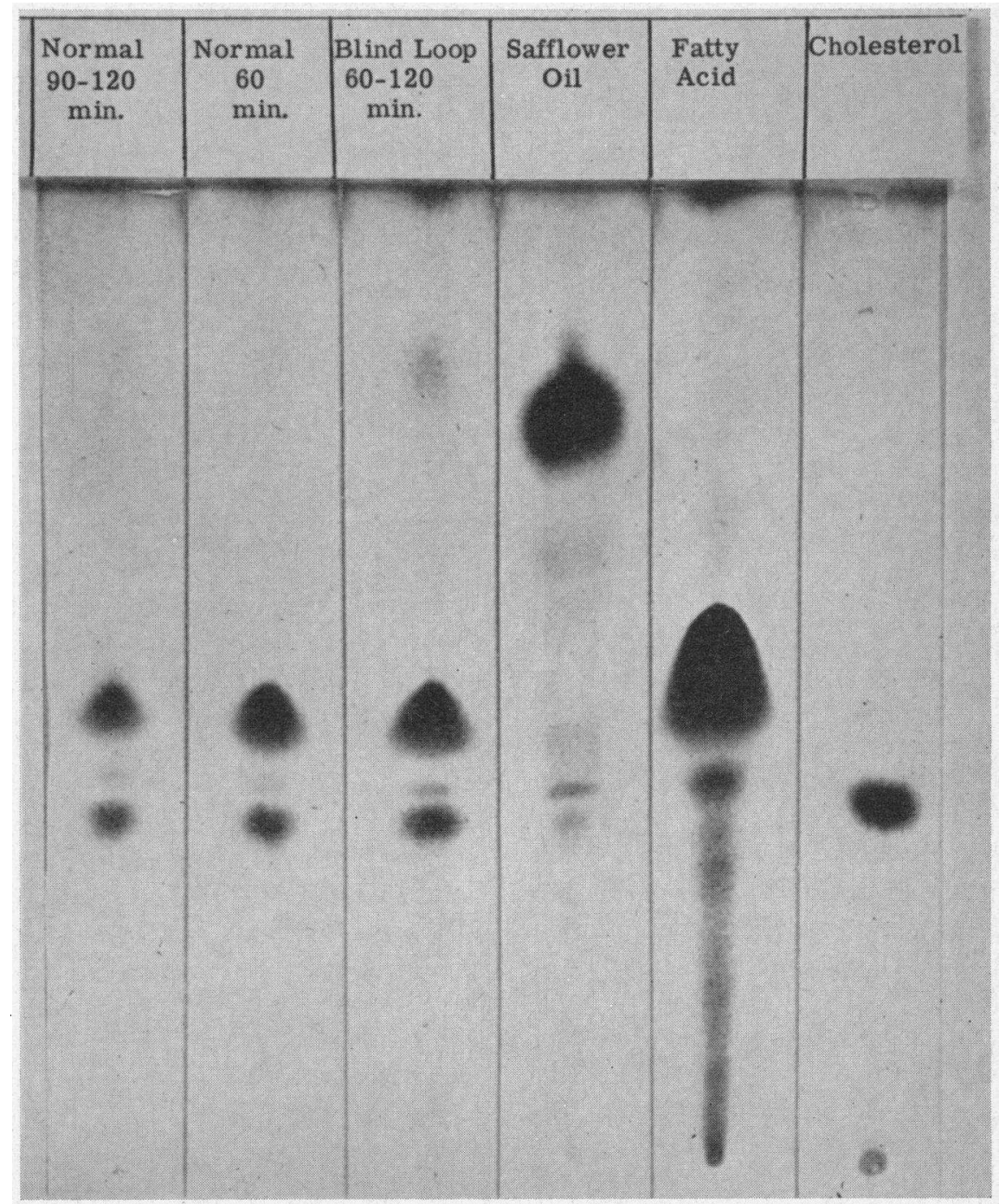

FIG. 4. : THIN LAYER CHROMATOGRAPH OF INTESTINAL CONTENT LIPID OF NORMAL AND BLIND LOOP DOGS AFTER A FAT-CONTAINING MEAL. Oleic acid and cholesterol standards are in the last two columns on the right. The safflower oil standard consists almost wholly of triglyceride. Times represent periods after instillation of fat-containing test meal.

distal to the stoma from three dogs with steatorrhea 7 months after construction of the blind loop. No abnormality was noted in these biopsies nor in a single specimen obtained from the loop itself.

\section{Discussion}

In the present study we have demonstrated marked abnormalities of bile acid metabolism in vivo in dogs with steatorrhea secondary to surgical construction of a jejunal blind loop. These changes include a high per cent of deconjugated bile acids within the small bowel and, as demon- strated within the loop itself, conversion of unconjugated acids to mono- and dihydroxy forms. Whether the deconjugation of bile acids noted in the jejunal content occurred during passage of the acids through the loop or took place within the jejunal lumen per se as a result of extension of the bacterial overgrowth from the loop is not established by this study.

In one blind loop animal, considerable deconjugation was also apparent in the gall bladder bile. Whether this resulted from bacterial overgrowth into the biliary system or failure of the liver to 
reconjugate absorbed nonconjugated bile acids is not clear. Both deconjugation and alteration of ring substitutions have been produced in vitro with bacteria isolated from normal feces (15-17). Furthermore, Donaldson (5) has demonstrated accumulation of dihydroxy acids in the blind loop contents in both rats and man. The mechanism by which these alterations in bile acids lead to impairment of fat absorption, which characterizes both experimental and naturally occurring blind loop, although previously suggested (18) has not been established.

Lipolysis, micelle formation, and re-esterification within the mucosal cell are among the processes in fat absorption known to involve bile acids. Findings in the present study as well as those previously reported (5) indicate that effects on lipolysis, if present at all, are minimal in the presence of blind loop steatorrhea. Since the action of pancreatic lipase is enhanced both by conjugated and unconjugated bile acids $(19,20)$, no effect on this enzymatic activity would be expected to result from the deconjugation of bile acids that occurs in blind loop.

In the present study, the formation of micellar lipid after a fat meal was shown to be defective in dogs in which blind loop had been produced. Hofmann and Borgström $(21,22)$ have shown that at the $\mathrm{pH}$ of intestinal content nonconjugated bile acids are largely in nonionic form and do not participate optimally in micelle formation. This may reflect either the limited solubility of unconjugated acids in micellar solutions at the $\mathrm{pH}$ of intestinal content $(23,24)$ or the selective binding of unconjugated acids to bacteria or other intestinal content residues (24). In contrast, conjugated acids have a lower $\mathrm{pK}$ value, are in ionic form, and readily form mixed micelles with the products of intestinal lipolysis-fatty acids and monoglyceride. It is possible that the demonstrated defect in micelle formation that occurs in the blind loop dog results from a deficiency of intraluminal conjugated bile acid resulting from the rapid deconjugation of biliary bile acids in the presence of intestinal overgrowth. The conversion of steatorrhea in this study by feeding large amounts of conjugated bile acids is consistent with this contention. Quantitative considerations support this line of reasoning. Under normal circumstances bile acid concentration in the small bowel lumen in man (essentially all in conjugated form) has been reported to be 6 to 10 mmoles per $\mathrm{L}(25$, 26). In the present study, deconjugation of 70 to $97.5 \%$ of the conjugated acids occurred. This would lower the concentration of conjugated acid to the range of 0 to 2 mmoles per $\mathrm{L}$, assuming total concentration to be the same as in normal man. These values are below the critical micellar concentration reported by Hofmann (26). It is important to emphasize that these figures are based on several assumptions proven neither for normal nor blind loop dogs, but they suggest that the degree of abnormality seen is the order of magnitude required to alter micelle formation.

Dawson and Isselbacher (18) have shown that re-esterification of fatty acids after entry into intestinal mucosal cells is greatly enhanced by conjugated bile acids, a process apparently separate from their effect on solubility within the lumen. These authors have further demonstrated that although nonconjugated cholic acid acts weakly to enhance esterification, deoxycholate, a bacterial product of cholic acid $(16,17)$, is inhibitory. They have suggested that bacterial alteration of bile acid structure in the blind loop syndrome could lead to impaired fat absorption. The demonstration in the present study that both deconjugation of bile acids and alteration of ring structure occur in the intestine of blind loop dogs is consistent with their hypothesis that the optimal bile acid composition for re-esterification is not present in this situation. The relative roles of impaired micelle formation and decreased re-esterification in the steatorrhea of blind loop are not certain. Although the present study documents that micelle formation is defective in blind loop steatorrhea, abnormal re-esterification has not been reported in vivo in this situation. Furthermore, the histological change described by Dawson and Isselbacher (18) produced by deoxycholate was not observed in the jejunal mucosa of animals with steatorrhea in the present or previous studies (5). In either case, the correction of fat absorption with bile acid feeding strongly supports the contention that the defect results from rapid deconjugation of bile acid by bacterial overgrowth in the intestinal lumen. It further suggests that the deficiency of conjugated acids, rather than abnormal accumulation of deconjugated forms, is critical, since it is likely that after taurocholic acid 
feeding in large doses the content of the nonconjugated products of bacterial action were present at high levels.

\section{Summary}

A jejunal blind loop was produced surgically in 12 dogs, and steatorrhea of up to $56 \%$ of dietary fat occurred within 2 to 7 months. Deconjugation of isotopic bile acids was demonstrated within the small intestine of these animals as well as within the blind loop itself, coincident with alteration in ring substitution. After a fat-containing meal, $2.2 \pm 5.0 \%$ of jejunal content lipid was in micellar phase in blind loop dogs compared to $56.5 \pm$ $35.6 \%$ in control animals. Steatorrhea was corrected by orally administered sodium taurocholate. These findings suggest that the altered bile acid metabolism present in these animals plays an important role in their impaired fat absorption, probably by interfering with optimal intraluminal micelle formation.

\section{Acknowledgments}

We are indebted to Drs. T. P. Almy, Parker Van Amee, and Rulon Rawson for their help throughout the study; and to Dr. Walter Lawrence for his assistance with surgical aspects. We are also indebted to $\mathrm{Mr}$. Richard Barters and Mr. Serge Denecko for their expert help with the care of the animals.

\section{References}

1. Kim, Y. S., N. Spritz, M. Blum, J. Terz, and P. Sherlock. Steatorrhea of blind loop syndrome: role of altered fatty acid and bile acid metabolism (abstract). Clin. Res. 1965, 13, 255.

2. Badenoch, J. Steatorrhea in the adult. Brit. med. J. 1960, 2, 963.

3. Watson, G. M., and L. J. Witts. Intestinal macrocytic anemia. Brit. med. J. 1952, 1, 13.

4. Panish, J. F. Experimental blind loop steatorrhea. Gastroenterology 1963, 45, 394.

5. Donaldson, R. M., Jr. Studies on the pathogenesis of steatorrhea in the blind loop syndrome. J. clin. Invest. 1965, 44, 1815.

6. Wirts, C. W., and F. Goldstein. Studies of the mechanism of postgastrectomy steatorrhea. Ann. intern. Med. 1963, 58, 25.

7. Bishop, R. F. Bacterial flora of the small intestine of dogs and rats with intestinal blind loops. Brit. J. exp. Path. 1963, 44, 189.

8. Tönnis, W., and A. Brusis. Veränderungen des morphologischen Blutbildes bei akuter und chronischer Darminhaltsstauung. Dtsch. Z. Chir. 1931, $233,133$.

9. Saxon, G. J. A method for the determination of the total fats of undried feces and other moist masses. J. biol. Chem. 1914, 17, 99.

10. Hofmann, A. F., and B. Borgström. The intraluminal phase of fat digestion in man: the lipid content of the micellar and oil phases of intestinal content obtained during fat digestion and absorption. J. clin. Invest. 1964, 48, 247.

11. Amenta, J. S. A rapid chemical method for quantification of lipids separated by thin-layer chromatography. J. Lipid Res. 1964, 5, 270.

12. Blum, M., and N. Spritz. The metabolism of intravenously injected isotopic cholic acid in Laennec's cirrhosis. J. clin. Invest. 1966, 45, 187.

13. Mangold, H. K. Thin layer chromatography of lipids. J. Amer. oil Chem. Soc. 1961, 38, 708.

14. Carey, J. B., Jr., and G. Williams. Metabolism of lithocholic acid in bile fistula patients. $\mathrm{J}$. clin. Invest. 1963, 42, 450.

15. Norman, A., and R. Grubb. Hydrolysis of conjugated bile acids by clostridia and enterococci. Acta path. microbiol. scand. 1955, 36, 537.

16. Norman, A., and J. Sjövall. On the transformation and enterohepatic circulation of cholic acid in the rat. J. biol. Chem. 1958, 233, 872.

17. Norman, A., and M. S. Shorb. In vitro formation of deoxycholic and lithocholic acid by human intestinal microorganisms. Proc. Soc. exp. Biol. (N. Y.) 1962, 110, 552.

18. Dawson, A. M., and K. J. Isselbacher. Studies on lipid metabolism in the small intestine with observations on the role of bile salts. J. clin. Invest. $1960,39,730$.

19. Vogel, W. C., and L. Zieve. A rapid and sensitive turbidimetric method for serum lipase based upon differences between the lipases of normal and pancreatitis serum. Clin. Chem. 1963, 9, 168.

20. Borgström, B. Studies on pancreatic lipase in Biochemical Problems of Lipids. Proceedings of the 2nd International Conference, University of Ghent, 1955, G. Popjak and E. LeBreton, Eds. London, Butterworth, 1956, p. 179.

21. Hofmann, A. F. Micellar solubilization of fatty acids and monoglycerides in bile salt solution in The Enzymes of Lipid Metabolism, P. Desnuelle, Ed. New York, Pergamon, 1961, p. 158.

22. Hofmann, A. F., and B. Borgström. Physico-chemical state of lipids in intestinal content during their digestion and absorption. Fed. Proc. 1962, 21, 43.

23. Ekwall, P., T. Rosendahl, and A. Sten. Studies on bile acid solutions. II. The solubility of cholic acid in sodium cholate solutions and that of desoxycholic acid in sodium desoxycholate solutions. Acta chem. scand. 1958, 12, 1622.

24. Norman, A. Fecal excretion products of cholic acid in man. Brit. J. Nutr. 1964, 18, 173.

25. Sjövall, J. On the concentrations of bile acids in the human intestine during absorption. Acta physiol. scand. 1959, 46, 339.

26. Hofmann, A. F. Clinical implications of physicochemical studies on bile salts. Gastroenterology $1965,48,484$. 